\title{
Monitoring the Northern Current in the Gulf of Lions with an observing system simulation experiment
}

\author{
AURÉLIE DUCHEZ ${ }^{1,2}$, JACQUES VERRON ${ }^{1}$, JEAN-MICHEL BRANKART ${ }^{1}$, \\ YANN OURMIÈRES ${ }^{3}$ and PHILIPPE FRAUNIÉ ${ }^{3}$ \\ ${ }^{1}$ LEGI, BP 53, 38041 Grenoble Cedex 9, France. \\ ${ }^{2}$ National Oceanography Centre, University of Southampton Waterfront Campus, European Way, \\ Southampton SO14 3ZH, UK. E-mail: A.Duchez@noc.ac.uk \\ ${ }^{3}$ LSEET, CNRS, BP 20132, 83957 La Garde Cedex, France.
}

\begin{abstract}
SUMMARY: The coastal circulation in the Gulf of Lions $(\mathrm{GoL})$ is influenced by the Northern Current (NC), forced by a complex wind system and also affected by important river discharges from the Rhône River. Correct modelling of this current is therefore important for obtaining a good representation of the gulf circulation. An observing system simulation experiment using the SEEK filter data assimilation method was used in a regional $1 / 16^{\circ}$ configuration of the GoL in the NEMO model. The synthetic observation database used for the experiment comprised altimetric data in addition to insitu temperature and salinity profiles. Statistical diagnostics and other physical criteria based on the improvement of NC representation were set up in order to assess the quality of this experiment. Comparisons between the free $1 / 16^{\circ}$ simulation and the experience with assimilation show that data assimilation significantly improved the description of the characteristics of the $\mathrm{NC}$ as well as its seasonal and mesoscale variability, which in turn improved the description of the water exchanges between the coastal region and the open sea.
\end{abstract}

Keywords: data assimilation, SEEK filter, OSSEs, Gulf of Lions, Northern Current, coastal processes, high-resolution modelling.

\begin{abstract}
RESUMEN: SUPERVISIÓN DE LA CORRIENTE DEL NORTE EN EL GOLFO DE LEÓN CON UN EXPERIMENTO DE SIMULACIÓN DEL SISTEMA DE OBSERVACIÓN. - La circulación costera en el Golfo de León (GoL) está a la vez influida por la Corriente del Norte del Mediterráneo (NC) y forzada por un sistema complejo de viento, así como las descargas importantes del río Rhône. Una correcta modelización de esta corriente es, por lo tanto, de importancia para tener una buena representación de la circulación en el golfo. Un experimento de simulación del sistema de observación mediante el método de filtro SEEK asimilación de datos se utiliza en una configuración regional 1/16 del GoL del modelo NEMO. La base de datos de observación sintética utilizada para el experimento se hace con los datos altimétricos además de la temperatura in situ y de los perfiles de salinidad. A fin de evaluar la calidad de este experimento, diagnósticos estadísticos y otros criterios físicos sobre la base de mejorar la representación del NC se han establecido. Las comparaciones entre la simulación libre 1/16 y el experimento con asimilación muestra que la asimilación de datos ha mejorado significativamente las características de los NC, así como su variabilidad estacional y de mesoescala, que a su vez ha mejorado el intercambio de agua entre la región costera y el mar abierto.
\end{abstract}

Palabras clave: asimilación de datos, SEEK filtro, OSSEs, Golfo de León, la corriente del norte del Mediterráneo, procesos costeros, modelización de alta resolución.

\section{INTRODUCTION}

The Gulf of Lions (hereinafter GoL) located in the northwestern Mediterranean Sea is a microtidal area in which the coastal circulation is influenced by the general circulation, in particular the Northern Current (hereinafter NC), and is also subjected to a large variety of atmospheric forcings. The Rhône River is the main river discharging in this area. Its freshwater river plume has a strong influence on the thermohaline characteristics of the shelf waters and has been analysed in numerous studies (Estournel et al. 2001, Reffray et al. 


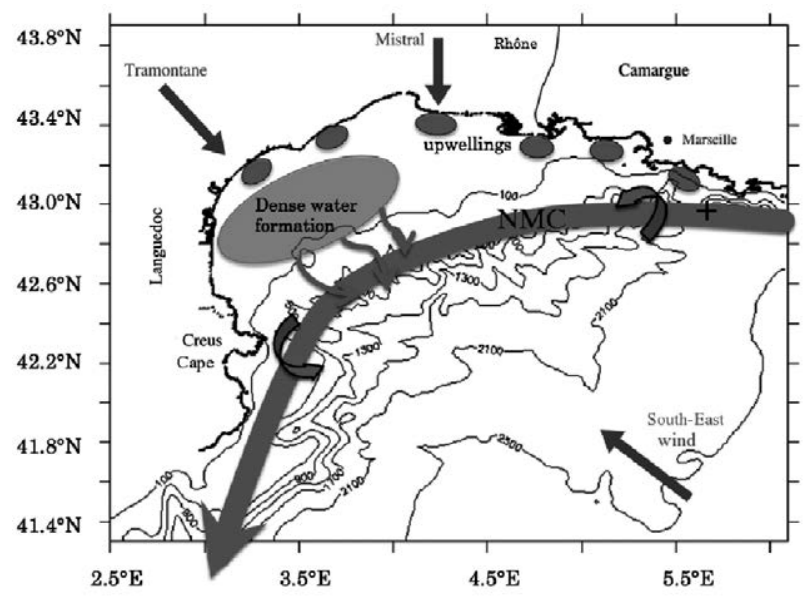

FIG. 1. - Bathymetry, main forcings and physical processes of the Gulf of Lions. Two continental winds (the Mistral and the Tramontane) and an oceanic wind, mainly blowing from the southeast, are represented. The Rhône River is the main river discharging in the Gulf of Lions. The large curved arrow represents the NC flowing near the coast from the Ligurian Sea to the Balearic Sea. Mesoscale activity of the NC, upwellings and dense water formation and cascading are also represented. The black cross (around $5.6^{\circ} \mathrm{E}, 43^{\circ} \mathrm{N}$ ) indicates the Blauquières Bank.

2004). In addition, winds have an important impact on the dynamics of this coastal area. Continental orography of the south of France makes winds blow in two directions: the Tramontane from the west/northwest and the Mistral from the north. In addition, southeast wind can also blow over this area, mainly in autumn and spring (Fig. 1).

Numerous physical processes characterize the ocean circulation in the GoL, such as coastal up- and downwellings (Millot 1979, Johns et al. 1992), winter dense water forming and cascading down the shelf break (Béthoux et al. 2002, Dufau-Julliand et al. 2004), local shelf circulation patterns (Estournel et al. 2003, Petrenko et al. 2005) and inertial and diurnal motions (Millot et al. 1981).

The NC is a coastal current constituting the north branch of the global cyclonic circulation of the northwestern Mediterranean Sea. This cyclonic loop is generated by Atlantic water entering the Mediterranean Sea through the Gibraltar Strait and is reinforced by the wind stress curl over the Liguro-Provencal Basin. This current is formed in the Ligurian Sea, and is composed of equal proportions of the East and West Corsica Currents (Millot 1990). It then flows westward along the Provencal coast until it reaches the continental bank of the GoL and then flows into the Balearic Basin. The numerous irregular canyons across the shelf edge have an impact on the path of the NC, which is known to be significantly guided by the bathymetry (Echevin et al. 2003). This current has a clear seasonal variability (Millot 1990, Conan and Millot 1995, Albérola et al. 1995). It is particularly complex to model during the winter due to its low width $(<30 \mathrm{~km}$ while it is between 40 and $60 \mathrm{~km}$ wide during the summer), deep depth (>250 m compared to a depth lower than 200 m during the summer), intensity (flux about 1.5-2 Sv, Petrenko 2003) and trajectory, which remains close to the continental slope. During this period, when the current is strongly influenced by the bathymetry, turbulent activity is enhanced and the NC generates $10-20 \mathrm{~km}$ amplitude meanders with wave lengths from around ten to one hundred kilometres as well as detaching eddies. This mesoscale activity is observed during the whole year by satellite imagery, although more eddies are observed during the winter ( $\mathrm{Hu}$ et al. 2009). After wind bursts, the NC can penetrate over the shelf: its variability, as well as the meanders and eddies that are associated with this current are responsible for a large part of the exchanges between the open ocean and the coastal waters (Albérola et al. 1995, Estournel et al. 2003, Johns et al. 1992).

It is therefore very important to simulate this current properly to obtain a realistic representation of the circulation in the GoL. In this study we thus used a regional configuration of the numerical model NEMO (Madec 2008): GDL16 (Langlais 2007) centred on the GoL, with a $1 / 16^{\circ}$ horizontal resolution similar to the operational configurations of the Mediterranean Sea (MFS, Pinardi et al. 2003; Mercator, Lellouche et al. 2005). In this area, where the first internal Rossby radius of deformation is less than $5 \mathrm{~km}$ over the shelf, a $1 / 16^{\circ}$ configuration can be considered as eddy-permitting. This implies that the modelled NC turbulent activity associated with small scale shelf processes can barely be represented. Bouffard et al. (2008) showed for example, that a high-resolution configuration of the northwestern Mediterranean Sea extracted from the SYMPHONIE numerical model (with a horizontal grid mesh of approximately 3 by $3 \mathrm{~km}$ ) did not provide realistic mesoscale and sub-mesoscale variability (to do so, they compared those model outputs with an improved altimetric data set). Moreover, Pinardi et al. (2003), Mounier et al. (2005), Echevin et al. (2003), André et al. (2005), Langlais (2007) and Ourmières et al. (2011) showed that a $1 / 16^{\circ}$ configuration can satisfactorily represent the gulf general circulation, but tends to simulate a NC with a trajectory and a turbulent activity that is slightly different than that observed and only begins to represent small scale processes.

Despite numerous oceanographic campaigns, this coastal region is far from being synoptically observed. Altimetric data presently available (altimetric satellite Topex/Poseidon, JASON1-2, ERS1-2, Envisat) are not reliable close to the coast and can only be used after a specific preliminary reprocessing (Birol et al. 2010, Bouffard et al. 2008), this latter method being still under development. This will be improved with the expected SARAL/AltiKa altimeter mission. This satellite, which will be launched in 2012, will provide almost real-time high-resolution data as close as $5 \mathrm{~km}$ from the coast and provide information about areas that are presently badly or partially observed, due to the capability of the Ka-Band (Vincent et al. 2006). Apart from this feature, SARAL/AltiKa will have the 
same space-time coverage as the ENVISAT altimetric satellite data.

A way to provide an integrated view of the observations and the model outputs is data assimilation. In addition, data assimilation is also a way to explore, through the so-called Observing System Simulation Experiment (OSSE) approach, the capability of future observing systems to describe ocean circulations. This is the approach that has been chosen for the present study, with the specific objective of determining whether a mixed data set made of altimetric data in conjunction with in-situ observations will be efficient enough for establishing the GoL circulation. Sensitivity studies have been performed to build a data assimilation experiment with the most appropriate characteristics as well as an optimal observation database. This OSSE is performed with GDL16. The synthetic data set used is made of altimetric data extracted along the track of the SARAL/AltiKa satellite in addition to in situ temperature and salinity profiles. All the data have been extracted from a regional configuration of $1 / 64^{\circ}$ resolution: GLazur64, allowing a satisfyingly realistic representation of the general circulation as well as the small scale processes occurring in the gulf.

The objectives of this experiment were to assess how to determine the structure, the trajectory, the thermohaline characteristics and the mesoscale activity of the $\mathrm{NC}$, and also to evaluate the impact of these changes on the characteristics of this current on the shelf and in offshore waters.

This article is divided into three main parts. The first part describes the tools used, i.e. modelling and data assimilation, and then describes the main characteristics of the OSSE performed. The second part, analyses the results: firstly, the statistical quality of the data assimilation experiment results is evaluated;

\section{GDL16}

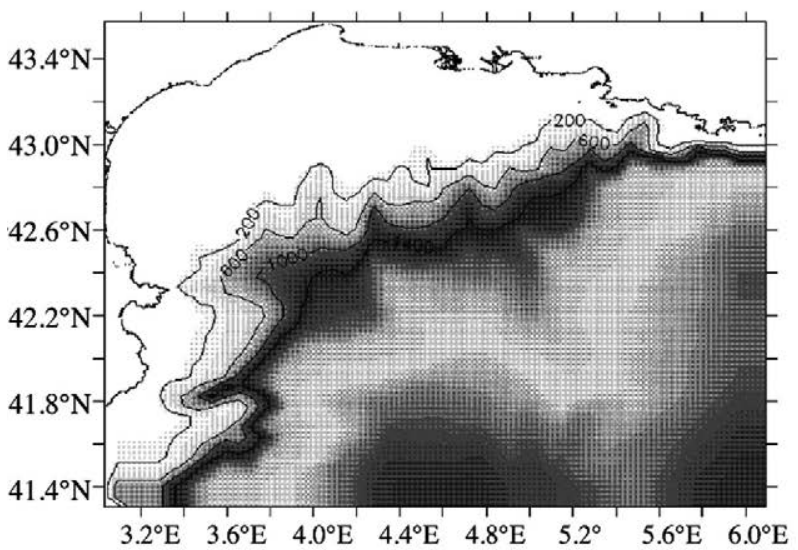

secondly, the improvement in the representation of this current due to data assimilation is assessed; and thirdly, the impact of the improvement in the representation of the NC on the mesoscale activity is analysed.

\section{MATERIALS AND METHODS}

\section{Gulf of Lions modelling}

The NEMO model used in this article is a threedimensional, z-level, primitive equation general circulation ocean model that uses the hydrostatic approximation with a free surface formulation (Madec 2008). A regional configuration GDL16 of the GoL (Langlais 2007) was extracted from a Mediterranean configuration (Béranger et al. 2005; Drillet et al. 2005) on a regular Mercator mesh with 36 vertical levels. The vertical level thickness extended from $6.6 \mathrm{~m}$ at the surface to $185.8 \mathrm{~m}$ at the bottom. Its domain extended from $3.09^{\circ} \mathrm{E}$ to $6.28^{\circ} \mathrm{E}$ in longitude and from $41.31^{\circ} \mathrm{N}$ to $43.61^{\circ} \mathrm{N}$ in latitude. Its topography and that of the configuration used to extract the observations of the data assimilation system (Fig. 2) are extracted from Berné and Satra (2002).

Radiation open boundary conditions were used at the limits of the modelled domain. The condition at the boundaries for the free surface was "zero pressure gradient" (Madec 2008). They came from the MED16ERA40 simulation, carried out with a rigid-lid $1 / 16^{\circ}$ regional configuration of the global Mediterranean Sea (Béranger et al. 2010) forced by the atmospheric forcing ERA40 (Uppala et al. 2005). Surface fluxes were provided using the bulk forcing approach, using the formula proposed by Large and Yeager (2004). This configuration was constrained by hourly atmospheric forcing of 18 by $18 \mathrm{~km}$ spatial resolution (Langlais

\section{GLazur64}

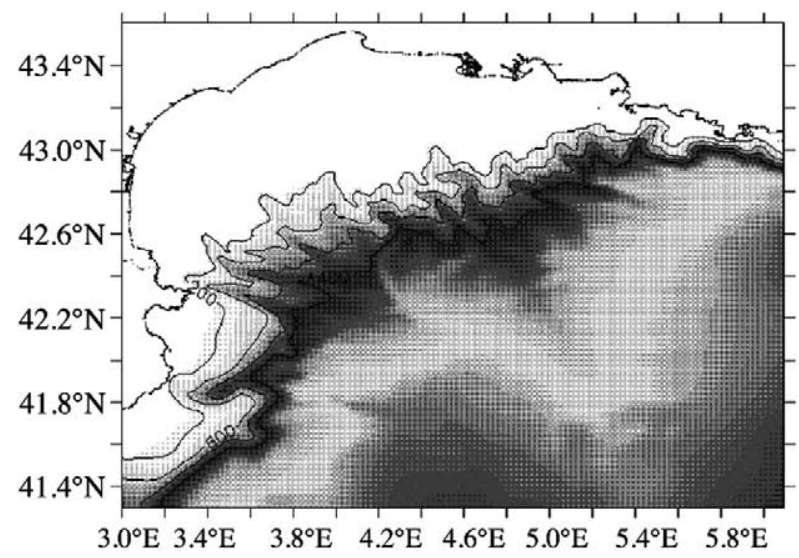

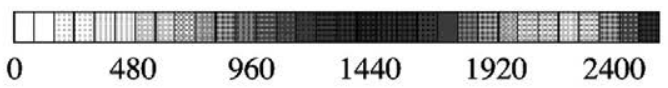

FIG. 2. - Topography (m) of the Gulf of Lions in the $1 / 16^{\circ}$ configuration: GDL16 (left panel) and the $1 / 64^{\circ}$ configuration: GLazur64 used to extract the observations (right panel). 
et al. 2009), computed from the REMO atmospheric model (Jacob et al. 2001). A biharmonic diffusion coefficient was chosen for the dynamics as well as the temperature and salinity. The TKE (Turbulent Kinetic Energy) scheme was selected to parameterize the processes of vertical mixing (Blanke and Delecluse 1993). The free simulation used in this paper consists of a hindcast simulation starting in January 1998, initialised with monthly temperature and salinity fields from the MEDATLAS climatology (MEDAR/MEDATLAS Group 2002) and integrated over three years (1 Jan 1998 to 31 Dec 2000).

\section{Data assimilation system}

The SEEK filter is a reduced order Kalman filter introduced by Pham et al. (1998) and presently used in the Mercator-Océan operational oceanography centre (Brasseur et al. 2005, Brasseur 2006). It is a sequential method as the information provided by the observations is introduced sequentially at each cycle when observations are available. It is based on the conventional Kalman filter reformulated with a low-rank approximation, which is presently the only manageable way when the Kalman filter is used in a realistic sized geophysical problem with state vectors of very large dimensions (Brasseur and Verron 2006). Classically, the analysis step of this algorithm combines at a given time the available data and the model predictions in a way that minimizes the error covariance of the corrected state, taking the observations and the model error into account. From this analysed state, a forecast step is then performed by integrating the model equations until new data are available. This method has been shown to provide similar results to other Kalman filter approaches, such as EnKF, at a similar or lower numerical cost (Brusdal et al. 2003). A standard state vector including the Sea Surface Height (hereafter SSH), the temperature, the salinity, and the zonal and meridional velocities was used in this study. The error statistics of this method were represented on a sub-space generally spanned by a small number of dominant 3D error directions, with a low-rank error covariance matrix defining the correlations between the state vector variables. A diagonal observation error matrix was used; correlated errors were then neglected. For altimeter products, this approach is acknowledged to be a realistic approximation. A simplification of the analysis scheme was adopted by enforcing to zero the error covariances between the distant variables that are believed to be uncorrelated in the real ocean in order to prevent data from having a spurious influence at remote distances through large-scale signatures in the 3D modes (Brankart et al. 2003). This simplification was implemented by assuming quite realistically that distant observations have a negligible influence on the local analysis. Since the SEEK algorithm is a local inverse algorithm, we assumed that each water column was only influenced by observations in a predeter- mined area, called the "influence bubble". A $35 \mathrm{~km}$ radius was selected for the influence bubbles. Inside these bubbles, the influence of the observations decreased exponentially away from the bubble's centre.

The SESAM algorithm, which implements the SEEK filter analysis scheme, was used in this study. Its main strength is its flexibility in assimilating a multivariate observation data set in a large variety of numerical models.

\section{OSSES}

\section{Definition}

When different scenarios are to be tested, the standard strategy in meteorology and oceanography is to perform Observing System Simulation Experiments (OSSEs). These kinds of experiments consist in using synthetic observations simulated by numerical models. The so-called observations extracted from a reference simulation considered as the "true ocean" are then assimilated into a control simulation (the "false ocean"). Through data assimilation, the control simulation is expected to converge towards the "true ocean". There are two kinds of OSSEs: "twin" and "cousin" experiments. In a twin experiment, observations are extracted from the same configuration as the configuration used for data assimilation, whereas in a cousin experiment, they are extracted from another configuration. This paper deals with a cousin experiment. For this experiment, the control simulation is the free simulation of GDL16 previously described. It will be called "GDL16-free".

\section{Observations with a $1 / 64^{\circ}$ configuration}

Observations were extracted from a simulation with a high-resolution configuration: GLazur64. The 1/16 ${ }^{\circ}$ configuration was used as the control run because it was not possible at this stage to use the $1 / 64^{\circ}$ configuration for the data assimilation experiments since even a free $1 / 64^{\circ}$ resolution simulation is extremely costly.

GLazur64 also uses the NEMO code and has 130 non-uniform vertical levels. Its vertical levels extend from $1 \mathrm{~m}$ at the surface to $32.6 \mathrm{~m}$ at the bottom. Its domain extends from $2.09^{\circ} \mathrm{E}$ to $7.97^{\circ} \mathrm{E}$ in longitude and from $41.26^{\circ} \mathrm{N}$ to $43.9^{\circ} \mathrm{N}$ in latitude so that it covers the trajectory of the NC from the Ligurian Sea to the Balearic Sea (Fig. 3). These dimensions are extended eastward compared to GDL16 and have the advantage of allowing a good representation of the NC in GLazur64 (as this current is created just before its eastern boundary). This enabled us to study the impact of the eastern open boundary on the characteristics of the NC in GDL16.

GLazur64 has the same hourly atmospheric forcing and the same open boundary conditions as GDL16. Whereas the $1 / 16^{\circ}$ configuration is eddy-permitting in the GoL, a $1 / 64^{\circ}$ configuration is eddy-resolving so that it has been shown to be in good agreement with 


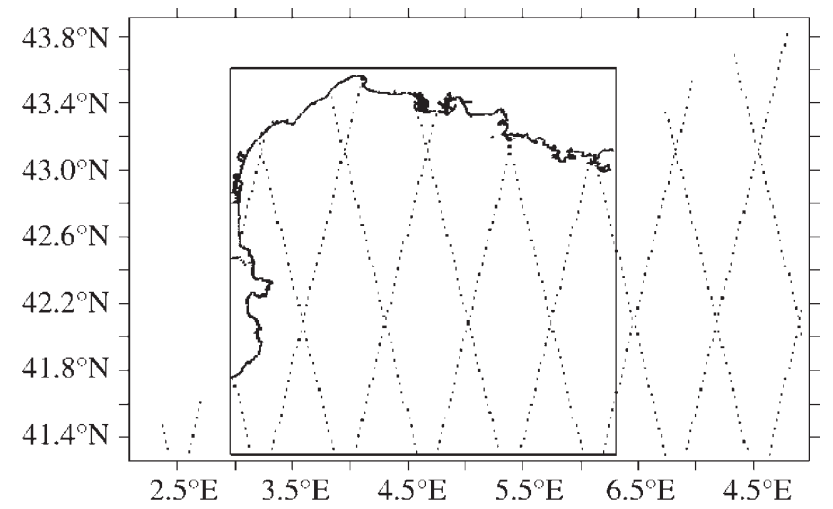

FIG. 3. - SARAL/AltiKa along-track SSH $(\mathrm{cm})$ extracted from the synthetic observation dataset over the experiment period, from 24 Jan to 23 Feb 1999 (30 days). The black frame shows the area of the numerical configuration used for data assimilation.

real observations available in the GoL. Even if GLazur64 has open boundaries that come from MED16ERA40 (Béranger et al. 2010), its extended eastward dimensions imply that the NC is more correctly represented and is therefore more able to flow closer to the coast. The position of this current at the entrance of the chosen domain for the GoL is thus in good agreement with real observations. Hence, the synthetic observation database used to perform these OSSEs has been completely extracted from GLazur64. This simulated database will be called "observations". The SSH observations extracted along the future tracks of the SARAL/AltiKa altimetric satellite (Fig. 3) in addition to temperature and salinity in-situ profiles extracted every $20 \mathrm{~km}$ (one profile over four on the $1 / 16^{\circ}$ model grid) constitute the observation database of the present OSSE experiment.

\section{Characteristics of GDL16-assim experiment}

We call the data assimilation experiment performed in this study "GDL16-assim". This experiment took place during the month of February 1999 (more precisely from 24 Jan to 23 Feb) since it is a period of the year when the NC has the most complex characteristics to determine, as explained in the introduction. Moreover, given that GDL16-free started in January 1998, the simulation was far enough from the initial conditions and the spin up stage was over (Duchez 2011).

For the assimilation to be efficient, or in other words for the control run to appropriately converge towards the observations, it is necessary to know the different system errors, i.e. the model and observation error covariance matrices. Since synthetic observations are used, it is considered that no error is due to the measurements, so that all the observation error is due to representativeness error. To take into account the difference of resolution between GDL16 and the observations, a low-pass Lanczos filter was applied to the observations. The standard deviation of the difference between the filtered outputs interpolated on the
$1 / 16^{\circ}$ grid and GDL16 was chosen to represent the observation error covariance matrix. Concerning the model error, the first 16 EOFs (Empirical Orthogonal Functions) of the differences between the outputs from the observations interpolated on a $1 / 16^{\circ}$ grid and the outputs from GDL16 were calculated to take into account the model variability that can be represented on such a grid.

The assimilation cycle lasted two days, as determined by sensibility studies, and the present experiment was conducted during 15 cycles. This experiment duration was chosen after performing a one year experiment that showed that, after more than thirty days, the convergence of the control run towards the observations remained steady: no improvement or deterioration of the quality of the experiment was found after one month.

The Incremental Analysis Updating (IAU) method was used following Ourmières et al. (2006) to correct the SSH, temperature, salinity and the zonal and meridional velocities at each model time step in a smooth temporal way. This method was adapted for the cousin experiments, since the first IAU increment was too large to be accepted by the model. The IAU increment was then divided into five parts and entered fully into the model after five assimilation cycles. The smooth simulation obtained after the application of this IAU increment was named the "assimilated state" (to avoid confusion with the analysis states, which are slightly different).

GDL16-assim was assessed with several diagnostics, such as statistical diagnostics and the use of criteria based on the improvement of the physics in the control run. These two methods will be discussed further below.

\section{RESULTS}

\section{Statistical assessment of the experiment}

The first criterion used to assess the quality of GDL16-assim is based on Root Mean Square (RMS) calculation.

$$
R M S=\sqrt{\frac{1}{N^{*} M} \sum_{i=1}^{N} \sum_{j=1}^{M}\left(y_{i, j}^{0}-H x_{i, j}^{a}\right)^{2}}
$$

at time $t$, where $i=1: \mathrm{N}$ represents longitudes and $j=1: M$ latitudes, $y^{0}$ represents the observations, $x^{a}$ represents the analysis state and $H$ is the observation operator that allows the transition between the model space and the observation space. This can be computed at time t over the whole area (from longitudes 1 to $N$ and latitudes 1 to $M$ ) between the observations and the model output (for example the analysis state in the above equation). Figure 4 shows an example for which the RMS differences are significantly reduced after a first stage of 10 days adjustment (corresponding to the 5 first cycles for which a fraction of the IAU increment is injected). Two different diagnostics have been set up to evalu- 

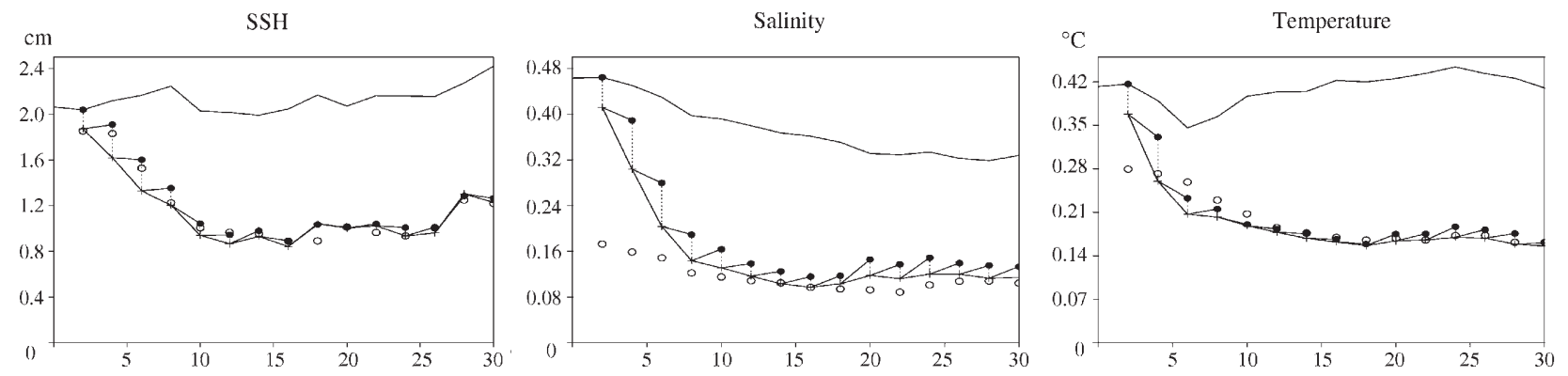

FIG. 4. - RMS difference from the observations calculated over the whole domain for a 30-day experiment for the SSH, the salinity and the temperature fields. The $\mathrm{x}$-axis represents time, the $\mathrm{y}$-axis represents RMS differences. The top black line represents the RMS deviation between GDL16-free and the observations, the black points represent the RMS deviation between the prevision states and the observations, the empty circles represent the deviation between the analysis states and the observations, and finally the grey curve represents the RMS deviation between the assimilated state and the observations.

ate the model's convergence towards the observations. The scores of the different state vector variables can be compared as both diagnostics are normalized. The first and more common one uses the mean of the RMS deviation during the last 10 days. It compares the convergence towards the observations of GDL16-free and GDL16-assim. In practice, this reduction percentage is given by calculating the mean RMS difference of GDL16-free and GDL16-assim over the last 10 days and then calculating the difference between these two means before dividing the result by the mean over the ten last days of GDL16-free, to normalize the result, and finally by multiplying by 100 to obtain a percentage. The higher the diagnostic is, the more successful is the assimilation experiment. For the experiment described in Figure 4, and with this first diagnostic, the RMS difference for the temperature is reduced by $60.3 \%$, the salinity by $70.6 \%$ and the SSH by $48.5 \%$.

The other diagnostic used aims to study the convergence of the simulation towards the observations during the last day of simulation (i.e. after 30 days of data assimilation). The difference between the RMS deviation of the last day of GDL16-free and GDL16-assim was calculated. After dividing this difference by the RMS deviation of the last day of GDL16-free (and multiplying it by 100), we finally obtained this second diagnostic. The final reduction percentage between GDL16-free and GDL16-assim was $62.7 \%$ for the temperature, $43.5 \%$ for SSH and $68.2 \%$ for salinity. With comparable results, these two diagnostics show that on the last day of the experiment as well as over the last ten days, GDL16assim converged significantly towards the observations. The error was significantly reduced by data assimilation.

These assessments are all based on statistical studies. However, the mathematical criteria do not give any information about how data assimilation improves the representation of the physics. Another complementary method for evaluating the successfulness of a data assimilation experiment, is to evaluate how much the ocean circulation is improved after data assimilation, in the sense of getting closer to the observations. Hence, through the study of the NC characteristics, a new quality criterion was defined based on improving the realism of the physics in GDL16.

\section{Monitoring the NC}

As mentioned above, being able to monitor the NC is of crucial importance in order to obtain a good representation of the dynamics over the whole region because the NC influences most of the dynamic features of this area (turbulent eddies on the shelf and offshore, Rhône River plume, water mass properties) and plays an important role in the exchanges between the shelf and the open sea.

As explained in the introduction, the $1 / 16^{\circ}$ resolution enables a good representation of the general circulation in the GoL, whereas small scale features as well as the structure and the trajectory of the NC are slightly different than in the observations. The reasons for these differences are the resolution and also the use of MED16-ERA40 as open boundary forcing, so that the NC enters the computed domain with slightly different characteristics than in the observations. Indeed, because the basin scale configuration used at the boundaries is not flawless it will tend to introduce some of its imperfections into the computed domain. However, we noticed that the ability of the MED16 configuration to reproduce a satisfying NC during wintertime depends greatly on the atmospheric forcing used. Indeed, the representation of this current in MED16 forced by the ECMWF analyses is in better agreement with the observations (Béranger et al. 2010, Ourmières et al. 2011). Consequently, from the eastern boundary to the southern boundary of GDL16, the NC is located too far off the coast of the Var and Marseilles region (especially at $6^{\circ} \mathrm{E}$ around the Blauquières bank shown in Fig. 1), and remains too wide during wintertime and hardly develops meanders (Fig. 5). Moreover, the resolution of the bathymetry cannot deal properly with the numerous canyons that significantly impact water exchanges through the shelf break.

Several levels of physical diagnostics are available for a data assimilation experiment. A successful data assimilation experiment should be firstly able to correct the variables of the state vector that are assimilated: this is the first physical diagnostic that will be used further to evaluate how the thermohaline properties of the NC converge toward the observations. A second physical 

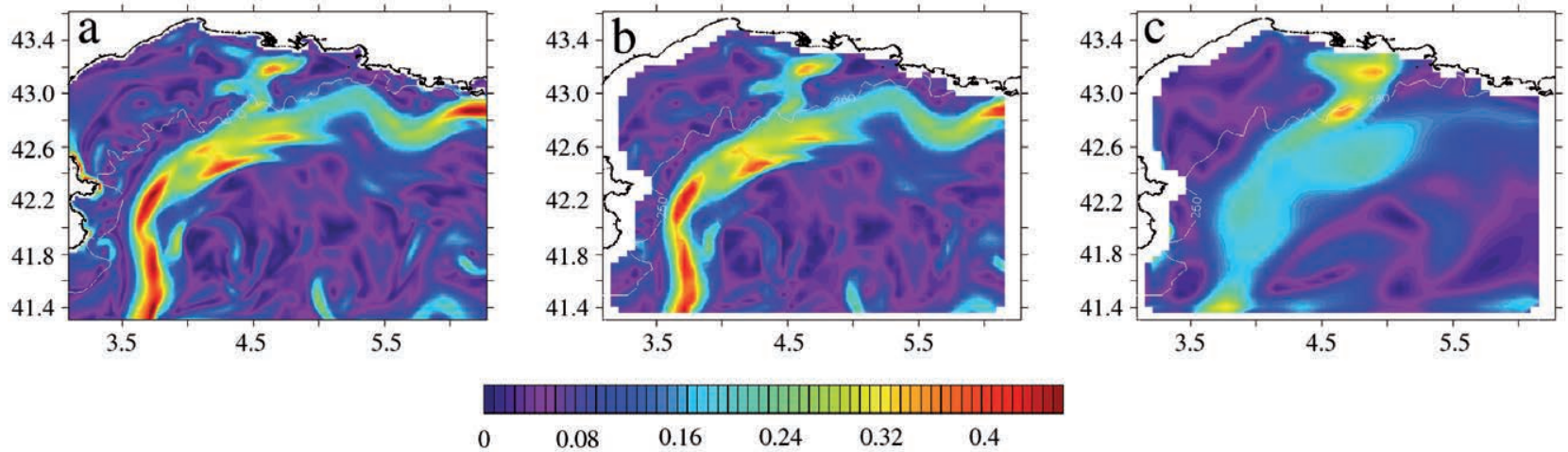

FIG. 5. - Current magnitude $\left(\mathrm{m} \mathrm{s}^{-1}\right)$ at the surface on $15 \mathrm{Feb}$ in the observations (a), in the observations interpolated on a $1 / 16^{\circ}$ grid (b) and in GDL16-free (c). These graphics only represent the area of GDL16. In the observations, the NC is narrow, flowing close to the coast near the eastern boundary. A NC meander clearly appears at $5.5^{\circ} \mathrm{E}$, whereas in picture $\mathrm{c}$, the $\mathrm{NC}$ is wide, weak and does not create any meander.

diagnostic consists in studying variables from the state vector that are not assimilated (i.e. the meridional and zonal velocities): this diagnostic is used to control the structure and the trajectory of the NC using the velocity components.

\section{Monitoring the $\mathrm{NC}$ thermohaline properties}

Water masses characterizing this current have a strong temperature and salinity signature, with a salinity higher than 38 and warm temperatures contrasting with the fresh water input coming from the Rhône River and the cold waters often due to the different offshore winds blowing over this area (frequently triggering upwellings). More generally, this current can be easily distinguished from the shelf and the open ocean water masses at any depth by the presence of a strong density gradient. TS diagrams can thus be used to characterize the different water masses flowing over the shelf break. Diagrams presented on Figure 6 represent water masses flowing over the shelf between $4.2^{\circ} \mathrm{E}$ and $5.4^{\circ} \mathrm{E}$ in longitude and $42.3^{\circ} \mathrm{N}$ and $43.4^{\circ} \mathrm{N}$ in latitude and between $70 \mathrm{~m}$ and $300 \mathrm{~m}$ in depth (i.e. mainly Atlantic Water). The colours on these figures represent a measure of the quantity of points with special TS characteristics. The black lines represent
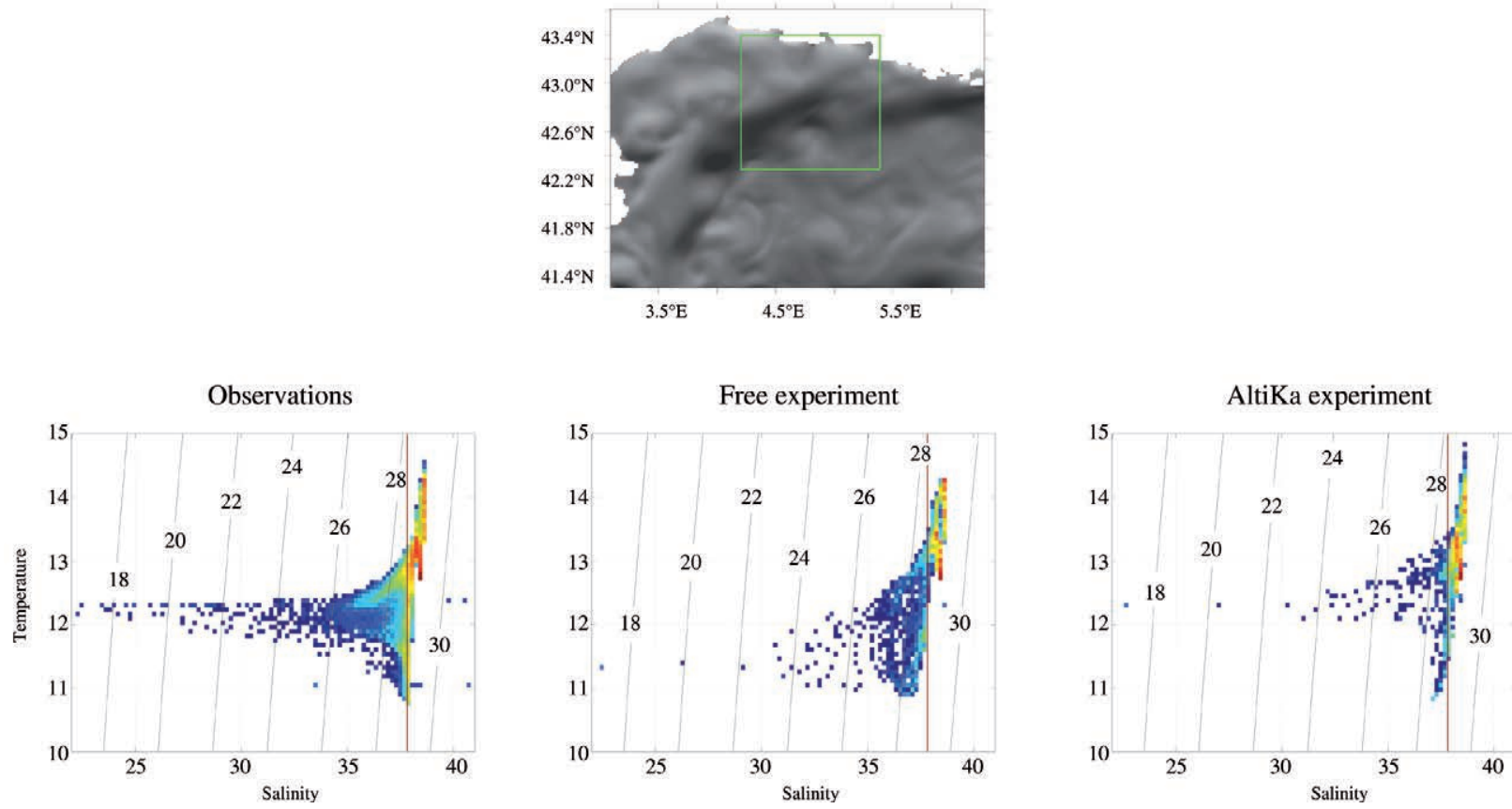

FIG. 6. - TS diagrams of water masses flowing over the shelf break. These waters flow between $70 \mathrm{~m}$ and $300 \mathrm{~m}$ in depth, between $4.2^{\circ} \mathrm{E}$ and $5.4^{\circ} \mathrm{E}$ in longitude and between $42.3^{\circ} \mathrm{N}$ and $43.4^{\circ} \mathrm{N}$ in latitude. These diagrams are shown for the observation (left panel), GDL16-free (middle panel) and GDL16-assim (right panel) on $23 \mathrm{Feb}$. The diagram colours represent the quantity of grid points with a given TS property (warmer colours represent a higher quantity of grid points, whereas colder colours represent a lower quantity). Black lines represent the isovalues of potential density referenced to the surface. The brown vertical line represents the isohaline 38 that was chosen to separate the shelf from the open sea. 


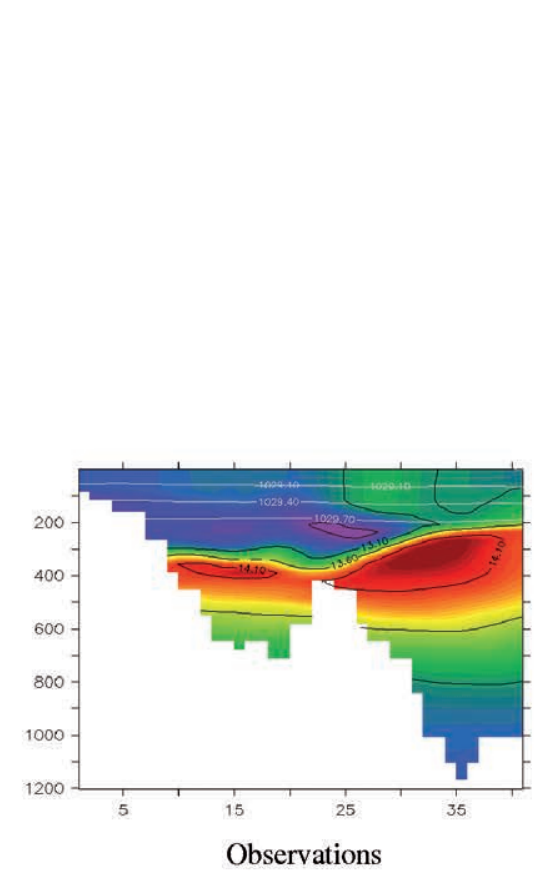

FIG. 7. - Cross section of temperature over the Lacaze-Duthiers canyon on $23 \mathrm{Feb}$ (final day of the assimilation experiment). The first line represents surface temperature in the observations and locates this canyon in the GoL. On the second line, the temperature cross section is represented on the left for the observations, in the middle for GDL16-free and on the right for GDL16-assim.

potential density isovalues referenced at the surface. The delimitation of the shelf and offshore waters is characterized by the isohaline 38 in GLazur64 (not shown). In the observations, the $\mathrm{NC}$ can be located on these diagrams as it is represented on each side of the shelf break and its waters are present in the highest quantity (warm colours). In GDL16-free, it can be seen that waters coming from the $\mathrm{NC}$ are located exclusively offshore and cover a lower range of temperatures than in the observations (range of $11-14.5^{\circ} \mathrm{C}$ in the observations versus $12-14.5^{\circ} \mathrm{C}$ in GDL16-free). Waters coming from the Rhône River are represented with the lowest temperatures and salinities and located in the left part of the diagrams. They are represented in GDL16-free with temperatures $1^{\circ} \mathrm{C}$ colder than the observations. In GDL16-free, it can be seen that there is a likely unrealistic water mass with salinities between 30 and 35 and temperatures between $11^{\circ} \mathrm{C}$ and $12^{\circ} \mathrm{C}$, and there is no a realistic warm and salted water mass at the surface.

In GDL16-assim, the thermohaline properties of the water coming from the Rhône River have been improved, illustrated by the appearance of a realistic water mass at the surface and the disappearance of the previous unrealistic water mass seen in GDL16-free. Finally, the NC properties are closer to the observed features: this current is thus located on each side of the shelf break with similar thermohaline properties.

Over the whole depth considered, the global TS characteristics of the NC and adjacent waters have thus been improved with data assimilation.

Figure 2 shows that the bathymetry of GDL16 is smoother than the one of the configuration used to ex- tract the observations: this has an important impact on the representation of the canyons. Indeed, the bathymetry accuracy is a limiting factor for the success of this kind of experiment. Figure 7 shows a cross section of the temperature over the Lacaze-Duthiers canyon. The $\mathrm{NC}$ core can be easily located with its high temperatures (around $14^{\circ} \mathrm{C}$ ) between $200 \mathrm{~m}$ and $600 \mathrm{~m}$ depth. Even if the temperatures of the first $300 \mathrm{~m}$ on the shelf are too cold in GDL16-free, it is warmer in GDL16assim, reaching better agreement with the observed temperatures. This figure clearly illustrates the problem of the $1 / 16^{\circ}$ bathymetry resolution with a canyon only reaching $500 \mathrm{~m}$ against $1200 \mathrm{~m}$ in the observations: this is then expected to make the NC occupy the entire water column, preventing the deep cold waters (around $12^{\circ} \mathrm{C}$ ) from flowing just underneath it, as represented in the observations. There is thus two reasons for the absence of the cold water mass that appears at the bottom in the observations but not in GDL16-free or GDL16-assim: firstly the bathymetry, and secondly the fact that a lower quantity of dense water is created in GDL16 during winter than in the observations (almost no dense water is created in a free simulation of GDL16 whereas it is created with data assimilation: Duchez 2011).

Again, it appears that performing data assimilation in a $1 / 16^{\circ}$ resolution configuration improves the representation of the TS properties of this current even if the bathymetry is likely to disturb the NC flowing along the shelf break. Following this analysis of the NC thermohaline properties, the next section focuses on its dynamical features, i.e. its trajectory and structure. 

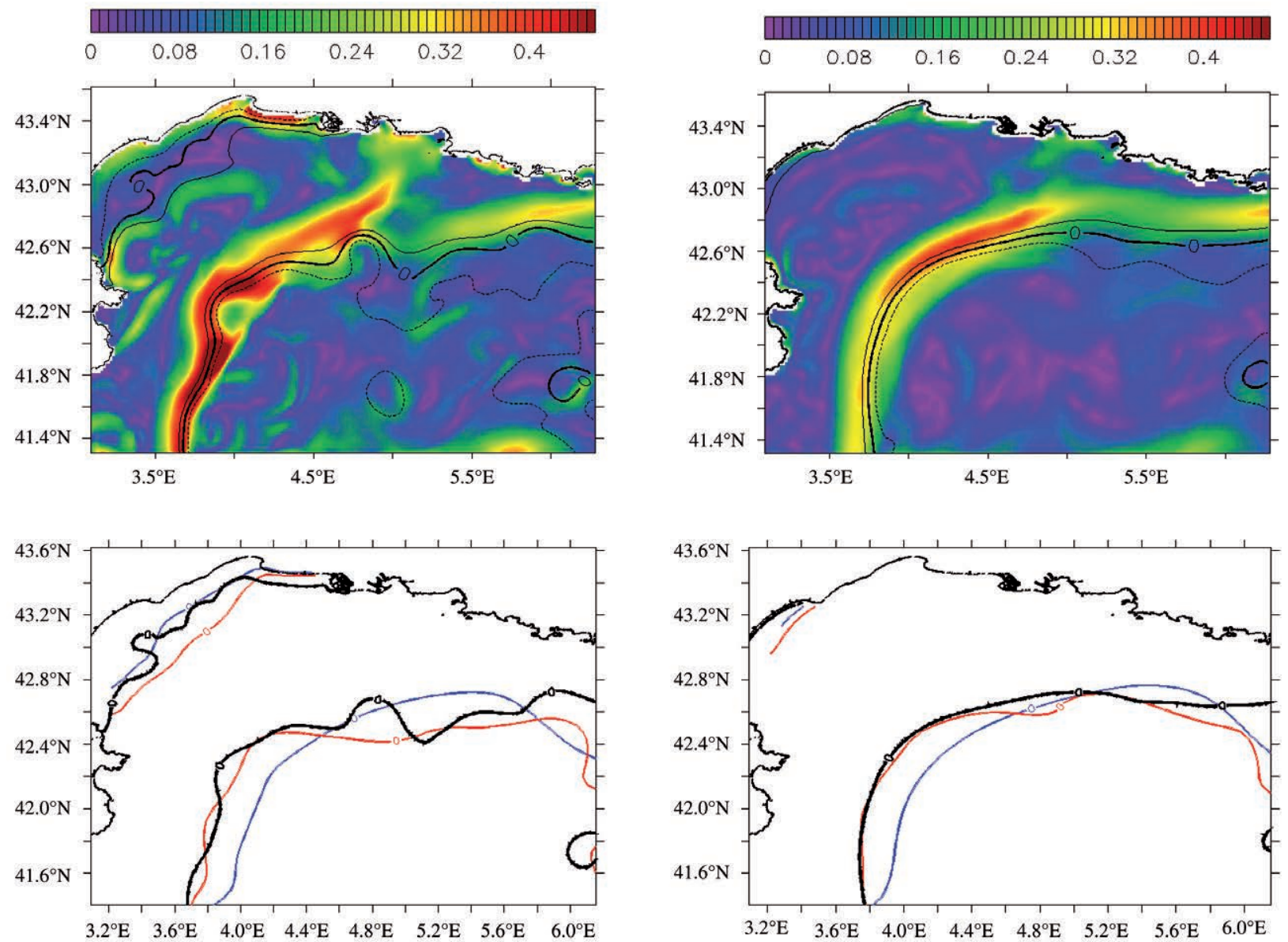

FIG. 8. - The NC is represented by iso-height lines equal to 0 . On the first line, the colours represent the velocity magnitude in the observations; the black line represents the iso-height lines equal to 0 . On the second line, the isolines of SSH equal to 0 are represented in black for the observations, blue for GDL16-free and red for GDL16-assim, highlighting the exterior edge of the NC. The left column shows the instantaneous trajectory during the last day of the experiment $(23 \mathrm{Feb})$ whereas the right column represents the data averaged over the last 20 days of the experiment (from 3 to $23 \mathrm{Feb}$ ).

\section{Control of the NC structure and trajectory}

Hereafter, the term structure relates to the $\mathrm{NC}$ body as evidenced from the current velocity amplitude in Figure 8 (first line). The term "structure" will then be used to define the characteristics of this current that allow it to be distinguished from the surrounding waters.

As seen in the introduction, the $\mathrm{NC}$ is associated with a density front, and these property differences make it easy to observe with altimetry data.

Figure 8 shows that the isoline zero of $\mathrm{SSH}$ is a good indicator of the NC trajectory, which makes it possible to compare the trajectory of the current in the three simulations. This current can be divided into two parts along its path: the first one (from $4.4^{\circ} \mathrm{E}$ to $6^{\circ} \mathrm{E}$ ) has mainly a zonal component whereas its second part (from $42^{\circ} \mathrm{N}$ to $41.4^{\circ} \mathrm{N}$ ) has mainly a meridional component. For its meridional part, data assimilation has significantly improved the trajectory of the current and GDL16-assim fits the observations well. For the zonal part $\left(4.4^{\circ} \mathrm{E}\right.$ to $\left.6^{\circ} \mathrm{E}\right)$, it appears that it is located south of its expected trajectory. This problem comes partially from a deficient $\mathrm{NC}$ position as introduced by MED16-ERA40 at the eastern boundary that data assimilation is not able to correct since this method has no impact on the open boundary forcing introduced every five days in the domain. This highlights the fact that even if data assimilation significantly improves the characteristics of the NC, boundary conditions still have a significant impact and introduce errors that can only be corrected far from the boundaries. In our case, it appears that MED16-ERA40 shows a NC that is systematically too far offshore. As a result, the $\mathrm{NC}$ introduced in the present computed domain has a similar flaw.

As shown in Figure 8, besides its signature in $\mathrm{SSH}$, the NC can be easily located in the GoL with its meridional and zonal velocities; these two variables are nonobserved variables in this data assimilation experiment. Therefore, the control resulting from data assimilation for these non-observed variables $(\mathrm{U}, \mathrm{V})$ constitutes a higher level of physical diagnostic for the experiment assessment. The NC velocity amplitude was calculated to determine its trajectory and structure. We then compared the simulations according to a criterion of veloc- 
ity amplitude of $0.06 \mathrm{~m} \mathrm{~s}^{-1}$ (Duchez 2011), which is a good indicator for the $\mathrm{NC}$ at $300 \mathrm{~m}$ depth and a good way to locate it on a vertical section.

Figure 9 shows this current at $300 \mathrm{~m}$ depth and on a meridional section of the GoL. The superposition of this isovalue of the $\mathrm{NC}$ velocity amplitude for the three simulations shows how data assimilation is able to narrow down this current, providing better agreement with the observed NC. When instantaneous data were used, for example (left panel), data assimilation extended the $\mathrm{NC}$ (represented in the section around $42.8^{\circ} \mathrm{N}$ ) from $42.6^{\circ} \mathrm{N}$ to $42.9^{\circ} \mathrm{N}$ in GDL16-assim as in the observations. In GDL16-free on the other hand, it extended from $42.7^{\circ} \mathrm{N}$ to $43.0^{\circ} \mathrm{N}$. These figures also show that improvements not only occur for the $\mathrm{NC}$ but also for the other surface currents flowing from the surface to $400 \mathrm{~m}$. The depth of the isoline $0.06 \mathrm{~m} \mathrm{~s}^{-1}$ was also improved by $50 \mathrm{~m}$.

This satisfactory control of the NC structure and trajectory obtained when directly observed data such as the velocity are considered shows that the SEEK filter is appropriately parameterized and is able to extrapolate from observed (SSH, temperature, salinity)
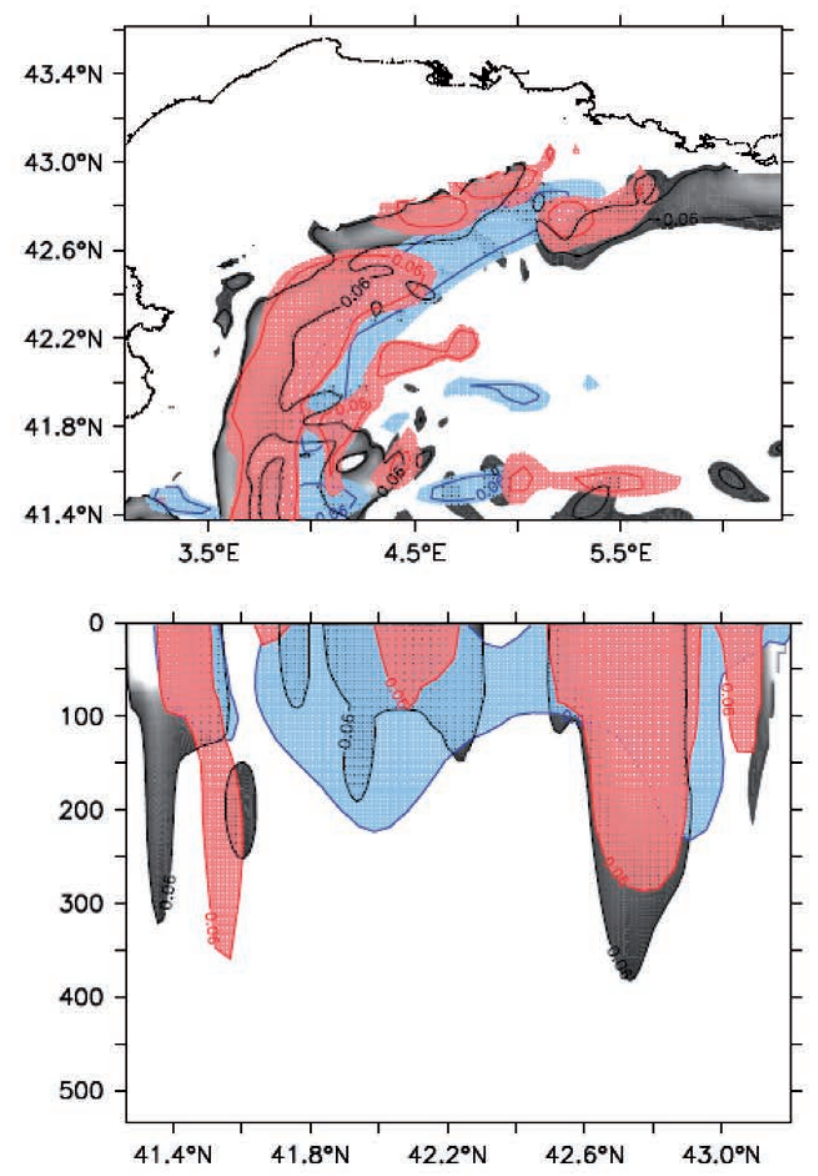

to non-observed variables (here $\mathrm{U}, \mathrm{V}$ ) along the directions represented by the error modes that connect all dynamical variables and grid points of the numerical model.

\section{Influence on the shelf mesoscale activity}

The turbulent activity of the NC is strongly enhanced in winter: this activity is represented well in the observations (Fig. 10). On 7 February, two main meanders appeared in the western part of the shelf in the observations and in GDL16-assim (represented by black arrows in the figure and documented in the literature: Hu et al. 2009), whereas without data assimilation, a $1 / 16^{\circ}$ resolution configuration displayed a $\mathrm{NC}$ that was too wide and not turbulent enough, and which would not be able to generate these kinds of structures. Recirculating branches of the NC create most of the meanders seen in this figure. Data assimilation also allowed us to represent three branches of this current detached from its main path that generate eddies exported offshore (one around $5.4^{\circ} \mathrm{E}$, another around $4.8^{\circ} \mathrm{E}$ and the last one around $4.2^{\circ} \mathrm{E}$ ). The main offshore eddy is
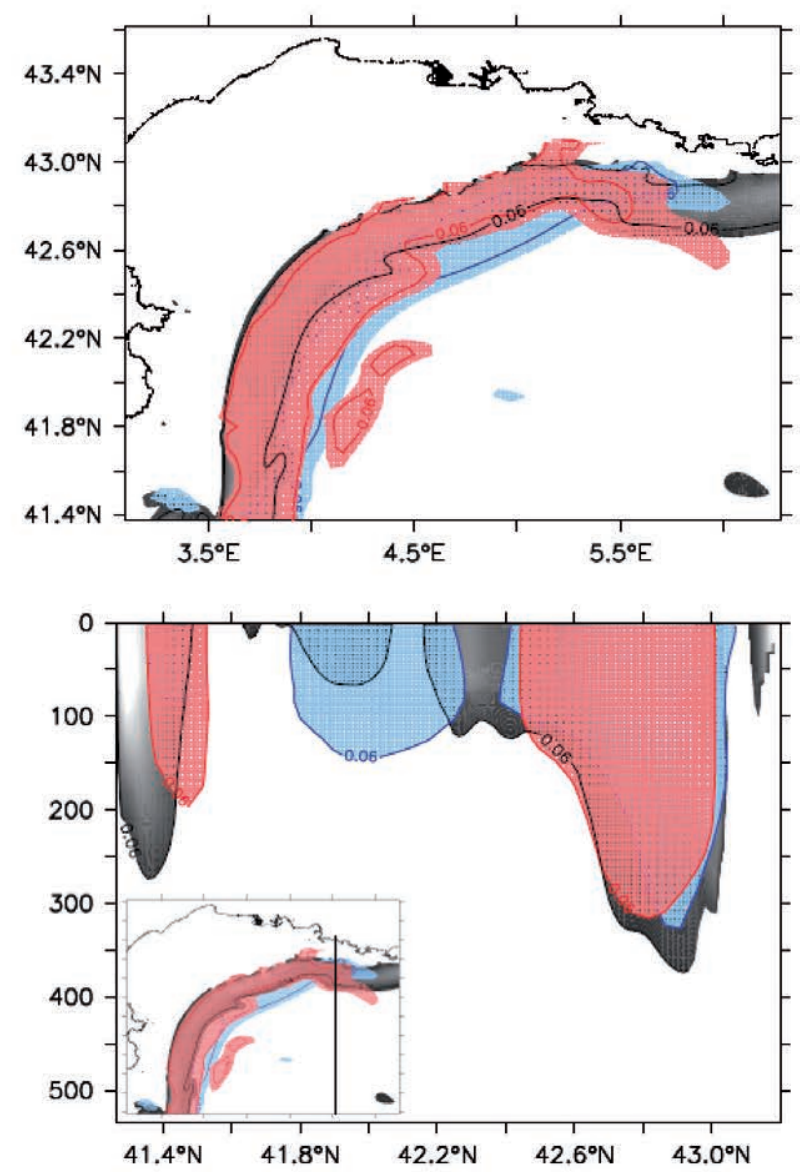

FIG. 9. - The $0.06 \mathrm{~m} \mathrm{~s}^{-1}$ velocity amplitude represented at $300 \mathrm{~m}$ depth (upper panels) and on a meridional section at $5.5^{\circ} \mathrm{E}$ (lower panels), in grey for the observations, in blue for GDL16-free and in red for GDL16-assim. In the lower right panel, the small picture indicates the location of this section in the GoL. The NC is represented by a deep and large patch around $42.8^{\circ} \mathrm{N}$. Left panels deal with instantaneous data on the last day of the data assimilation experiment (Feb. 23), whereas averaged data over the last 20 days of the experiment are represented in the right panel. 

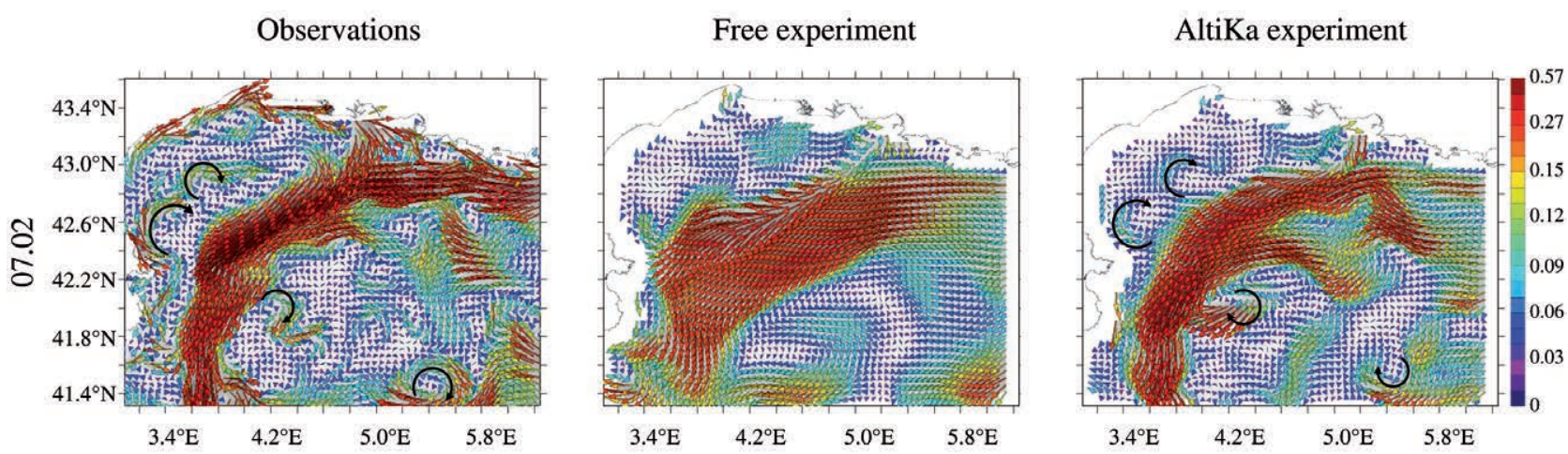

FIG. 10. - Surface speed for the $7^{\text {th }}$ cycle (7 Feb) in the observations (left panel), GDL16-free (middle panel) and GDL16-assim (right panel) highlighting the mesoscale activity in the GoL. Anticyclonic eddies are indicated with black arrows.

centred on $5.4^{\circ} \mathrm{E}, 41.4^{\circ} \mathrm{N}$. Data assimilation was thus able to add sub-mesoscale/mesoscale information to the eddy-permitting GDL16 configuration by representing this observed offshore eddy in GDL16-assim.

In addition to a good description of the NC characteristics, the lack of turbulent activity evidenced in GDL16-free was clearly enhanced in GDL16-assim. Figure 10 shows a strong coastal jet appearing on the observed west coast currents. This eastward jet is due to a strong southeast wind event during the days prior to 7 February. This wind event was associated with a buoyancy forcing of the Rhône plume that forces the surface waters to be confined towards the coast and then deviate eastward with the Coriolis effect, which moves water masses to the right in the northern hemisphere. This strong thin jet flows too close to the coast to be represented on a $1 / 16^{\circ}$ grid and is located in a non-observed area, which explains why it cannot be observed with or without data assimilation. Consequently, and despite encouraging improvements in the NC characteristics and turbulent activity, some features appearing in the observations are unlikely to be reproduced on a $1 / 16^{\circ}$ grid.

\section{CONCLUSION AND SUMMARY}

The aim of this study was to assess the impact of data assimilation on the path, the structure, the turbulent activity and the thermohaline characteristics of the NC. To do so, the SEEK filter data assimilation algorithm was implemented in a $1 / 16^{\circ}$ configuration of the GoL (GDL16) to perform an observing system simulation experiment (OSSE).

The synthetic observation database used for this experiment was extracted from a $1 / 64^{\circ}$ configuration (GLazur64) as its simulated circulation characteristics are in good agreement with the observations available in this area. This database displays a realistic NC as well as small scale features like coastal upwellings, coastal jets and turbulent activity close to the related observations in the real ocean. The $1 / 16^{\circ}$ resolution allows a satisfactory representation of the general circulation, by modelling the $\mathrm{NC}$ with correct overall characteristics, but with insufficiently accurate seasonal and mesoscale variability: during the winter this current is too wide, flows too far from the coast, has temperatures that are too cold,salinities that are too low and displays turbulent activity that is too weak.

The discrepancies between the representation of the NC in a free simulation of GDL16 and in the observations is mainly due to the difference in the horizontal and vertical resolution, as well as the difference in their respective bathymetry, since the canyons are shallower in GDL16 than in the observations (Ourmières et al. 2011). Finally, these differences are also due to the imperfect dynamical features introduced at the eastern open boundary by the global $1 / 16^{\circ}$ configuration of the Mediterranean Sea (MED16-ERA40).

The parameterizations chosen for the SEEK filter in this OSSE significantly improved the representation of the physics in this area and more particularly, the NC simulation. A first statistical assessment of the experiment showed an important decrease in the error (difference between a free simulation and the observations). By means of physical diagnosis, we managed to assess the improvement due to the assimilation regarding the NC trajectory and structure. This experiment has also shown a significant correction of the TS characteristics of this current. Indeed, a realistic water mass that did not exist in the free simulation appeared in the assimilated experiment in good agreement with the observations. Correctly simulating this current as well as recirculation branches breaking away from it makes it possible to better represent the subsequently formed eddies, and thus enhances the description of the mesoscale activity on the shelf and offshore, which results in a better regulation of the exchanges between the coastal area and the open sea.

Indeed, the interactions between the current and the topography (i.e. the steep shelf break) have an important impact on the trajectory and the strength of the incoming or out-going water masses on the continental shelf (Auclair et al. 2001).

However, even with data assimilation, a $1 / 16^{\circ}$ configuration cannot represent features smaller than $5 \mathrm{~km}$, including coastal processes like coastal jets on 
the west coast of the gulf (Fig. 10), and these processes have a significant impact on the shelf turbulent activity. The bathymetry design and more particularly the canyons imperfectly represented in GDL16 also prevent the NC from being correctly represented. Finally, the eastern boundary that comes from MED16ERA40 is another limiting factor, as a good representation of the $\mathrm{NC}$ over the GoL is strongly conditioned by its entrance in the gulf, i.e. at the eastern open boundary. However in spite of these various remaining weaknesses regarding the $\mathrm{NC}$ representation, data assimilation allowed us to improve the modelling (with regard to the free simulation) of other shelf features like coastal upwellings, dense water formation, convection and cascading. Data assimilation has also allowed us to refine the Rhône river plume shape and expansion, which in turn has improved the description of the TS characteristics of the shelf waters, for instance with filaments of that plume being advected by the NC (not shown in the article).

Considering the assimilation of data that could come from future observation systems, the present study aimed to demonstrate the kinds of information that can be determined in the present operational ocean forecasting systems $\left(1 / 16^{\circ}\right.$ resolution regional configuration: Pinardi et al. 2003) for eventual coastal applications. To summarize, the main outlines arising from this study are that assimilating these kinds of data significantly improves the description of the $\mathrm{NC}$ characteristics, the mesoscale activity of the gulf and also the representation of small scale features on the shelf.

This study has highlighted the impact of data assimilation on a free $1 / 16^{\circ}$ configuration to improve the description of the circulation in the GoL. It has shown that using $1 / 16^{\circ}$ as a resolution for operational systems could provide even more information than what these models presently provide, if higher resolution observations are assimilated (giving access to sub-mesoscale/mesoscale information). The next step of this work will thus be to work with real observations: using all the available altimetric data and in situ measurements (coming from MOOSE (Mediterranean Ocean Observation Multi-Sites on Environment) lines from example). From a more technical point of view and still focusing on the improvement of the circulation in this area it will be possible to use other methods involving data assimilation. One solution could be to include open boundaries in the state vector so that they could evolve during the data assimilation experiment. Finally, data assimilation inside GLazur64, used in this article to extract the observations, could be used to perform twin experiments and then experiments using real observations. This was not possible at this stage due to the cost of the $1 / 64^{\circ}$ numerical experiments but this should evolve quickly in the near future. The present performance of data assimilation at only a $1 / 16^{\circ}$ resolution is very encouraging for further data assimilation experiments at higher resolutions.

\section{ACKNOWLEDGEMENTS}

This work was carried out at the laboratory LEGIMEOM (Grenoble, France). It was supported by French Minister of Education and University and the French Space Agency (CNES). Part of the numerical work was performed using the GENCI-IDRIS resources (grant 2010011707). We thank C. Langlais who created the configurations GDL16 and GLazur64, K. Béranger and Mercator Ocean for providing the ocean open boundary forcing and the Max Planck Institute of Meteorology for providing the REMO forcing. The authors thank the reviewers for their thoughtful comments that significantly helped to improve the manuscript.

\section{REFERENCES}

Albérola C., Millot C., Font J. 1995. On the seasonal and mesoscale variabilities of the northern current during the PRIMO-0 experiment in the western Mediterranean Sea. Oceanol. Acta 18(2): 163-192.

André G., Garreau P., Garnier V., Fraunié P. 2005. Modelled variability of the sea surface circulation in the western Mediterranean sea and In the gulf of Lions. Ocean Dyn. 55: 458-475.

Auclair F., Marsaleix P., Estournel C. 2001. The penetration of the Northern Current over the Gulf of Lions (Mediterranean) as a downscaling problem. Oceanol. Acta 24: 529-544.

Béranger K., Mortier L., Crépon M. 2005. Seasonal variability of water transport through the Straits of Gibraltar, Sicily and Corsica, derived from a high-resolution model of the Mediterranean circulation. Prog. Oceanogr. 66: 341-364.

Béranger K., Drillet Y., Houssais M.-N., Testor P., Bourdallé-Badie R., Alhammoud B., Bozec A., Mortier L., Bouruet-Aubertot P., Crépon M. 2010. Impact of the spatial distribution of the atmospheric forcing on water mass formation in the Mediterranean Sea. J. Geophys. Res. 115: C12041, doi:10.1029/2009JC005648.

Berné S., Satra C. 2002. Carte morpho-bathymétrique du Golfe du Lion. Notice explicative. Edition IFREMER Région Languedoc-Roussillon, $48 \mathrm{pp}$.

Béthoux J., Durrieu de Madron X., Nyffeler F., Tailliez D. 2002. Deep water in the Western Mediterranean: peculiar 1999 and 2000 characteristics, shelf formation hypothesis, variability since 1970 and geochemical inferences. J. Mar. Syst. 33-34: $117-131$.

Birol F., Cancet M., Estournel C. 2010. Aspects of the seasonal variability of the Northern Current (NW Mediterranean Sea) observed by altimetry. J. Mar. Syst. 81: 297-311.

Blanke B., Delecluse P. 1993. Variability of the tropical atlantic ocean simulated by a general circulation model with two different mixed-later physics. J. Phys. Oceanogr. 23: 1363-1388.

Bouffard J., Vignudelli S., Herrmann M., Lyard F., Marsaleix P., Menard Y., Cipollini P. 2008. Comparison of ocean dynamics with a regional circulation model and improved altimetry in the North-Western Mediterranean. Terr. Atmos. Ocean. Sci. 19: $117-133$.

Brankart J.M., Testut C.E., Brasseur P., Verron J. 2003. Implementation of a multivariate data assimilation scheme for isopycnic coordinate ocean models: Application to a 1993-96 hindcast of the North Atlantic Ocean circulation. J. Geophys. Res. 108: 3074.

Brasseur P. 2006. Ocean Data Assimilation using Sequential Methods based on the Kalman Filter. In: Verron J., Chassignet E. (eds.), GODAE, an Integrated View of Oceanography: Ocean Weather Forecasting in the 21st Century. Kluwer Academic Press, pp. 577.

Brasseur P., Bahurel P., Bertino L., Birol F., Brankart J.M., Ferry N., Losa S., Remy E., Schröter J., Skachko S., Testut C.E., Tranchant B., Van Leeuwen P.J., Verron J. 2005. Data assimilation for marine monitoring and prediction: the Mercator operational assimilation systems and the MERSEA developments. Q. J. R. Meteorol. Soc. 131: 3561-3582.

Brasseur P., Verron J. 2006. The SEEK filter method for data assim- 
ilation in oceanography: a synthesis. Ocean Dyn. 38(2): 93-121.

Brusdal K., Brankart J.M., Halberstadt G., Evensen G., Brasseur P., Van Leeuwen P.J., Dombrowsky E., Verron J. 2003. A demonstration of ensemble-based assimilation methods with a layered OGCM from the perspective of operational ocean forecasting systems. J. Mar. Syst. 40-41: 253-289.

Conan P., Millot C. 1995. Variability of the northern current off Marseilles, Western Mediterranean Sea from February to June 1992. Oceanol. Acta 18(2): 193-205.

Cummings J., Bertino L., Brasseur P., Dombrowsky E., Fukumori I., Martin M., Kamachi M., Mogensen K., Oke P., Verron J., Weaver A. Ocean data assimilation systems for GODAE. Oceanography. 22. No3.

Drillet Y., Bourdallé-Badie R., Siefridt L., Le Provost C. 2005. Meddies in the Mercator North Atlantic and Mediterranean Sea eddy-resolving model. J. Geophys. Res. 110: C03016, doi:10.1029/2003JC002170.

Duchez A. 2011. Contrôle de la circulation du golfe du Lion par l'altimétrie d'AltiKa : une approche par simulation du système d'observation. Ph.D. thesis, Univ. Toulon Var, 265 pp.

Dufau-Julliand C., Marsaleix P., Petrenko A., Dekeyser I. 2004. Three-dimensional modeling of the Gulf of Lions' hydrodynamics (northwest Mediterranean) during January 1999 (MOOGLI3 experiment) and late winter 1999: Western Mediterranean Intermediate Water's (WIW's) formation and its cascading over the shelf break. J. Geophys. Res. 109, C11, 002, doi: 10.1029/2003JC002,019.

Echevin V., Crépon M., Mortier L. 2003. Simulation and analysis of the mesoscale circulation in the northwestern Mediterraean Sea. Ann. Geophys. 21: 281-297.

Estournel C., Broche P., Marsaleix P., Devenon J.L., Auclair F., Vehil R. 2001. The Rhône River plume in unsteady conditions: numerical and experimental results. Estuar. Coast. Shelf Sci. 53: 25-38.

Estournel C., Durrieu de Madron X., Marsaleix P., Auclair F., Julliand C., Vehil R. 2003. Observation and modelisation of the winter coastal oceanic circulation in the Gulf of Lions under wind conditions influenced by the continental orography (FETCH experiment). J. Geophys. Res. 108(C3), 8059.

Flexas M., Durrieu de Madron X., Garcia M., Canals M., Arnau P. 2002. Flow variability in the Gulf of Lions during the matter HFF experiment (March-May 1997). J. Mar. Syst. 33-34: 197-214.

Hu Z. Y., Doglioli A., Marsaleix P., Dekeyser I. 2009. Numerical simulation of eddies in the Gulf of Lions. Ocean Modelling 28 : 203-208.

Jacob D., Andrae U., Elgered G., Fortelius C., Graham L.P., Jackson S.D., Karstens U., Koephen C., Lindau R., Podzun R., Rockel B., Rubel F., Sass H.B., Smith R.N.D., Van den Hurk B.J.J.M., Yang X. 2001. A comprehensive model intercomparison study investigating the water budget during the BALTEXPIDCAP period. Meteorol. Atmosp. Phys. 77 (1-4): 19-43.

Johns B., Marsaleix P., Estournel C., Vhil R. 1992. On the winddriven coastal upwelling in the Gulf of Lions. J. Mar. Syst. 3: 309-329.

Jordi A., Orfila A., Basterretxa G., Tintoré J. 2005. Shelf-slope exchanges by frontal variability in a steep submarine canyon. Prog. Oceanogr. 66(2-4): 120-141.

Langlais C. 2007. Etude de la variabilité interannuelle des échanges côte-large: simulation haute resolution de la dynamique du Golfe du Lion. Ph.D. thesis, Univ. Toulon Var, $282 \mathrm{pp}$.

Langlais C., Barnier B., Molines J.M., Fraunié P., Jacob D., Kotlarski S. 2009. Evaluation of a dynamically downscaled atmospheric reanalyse in the prospect of forcing long term simulations of the ocean circulation in the Gulf of Lions. Ocean Modelling 30: $270-286$
Large W.G., Yeager S.G. 2004. Diurnal to decadal global forcing for ocean and sea-ice models. NCAR technical notes, 18-221.

Lellouche J. M., Greiner E., Benkiran M. October 2005. PSY2V2, Le nouveau prototype opérationnel haute résolution de Mercator. Mercator-Océan Newsletter, No19.

Madec G. 2008. NEMO Ocean General Circulation Model reference Manuel. Internal Report. LODYC/IPSL, Paris.

MEDAR/MEDATALS 2002 Database. Cruise inventory, observed and analysed data of temperature and bio-chemical parameters (4 CD-ROMS)

Millot C. 1979. Wind induced upwellings in the Gulf of Lions. Oceanol. Acta 2(3): 261-274.

Millot C., Crépon M. 1981. Inertial oscillations on the continental shelf of the Gulf of Lions - observation and theory. J. Phys. Oceanogr. 11(5): 639-657.

Millot C. 1990. The Gulf of Lions' hydrodynamics. Cont. Shelf Res. 10(9-11): 885-894.

Mounier F., Echevin V., Mortier L., Crépon M. 2005. Analysis of the mesoscale circulation in the occidental Mediterranean Sea during winter 1999-2000 given by a regional circulation model. Prog. Oceanogr. 66(2-4): 251-269.

Ourmières Y., Brankart J.M., Berline L., Brasseur P., Verron J. 2006. Incremental Analysis Update implementation into a sequential ocean data assimilation system. J. Atmos. Ocean Tech. 23(12): 1729-1744.

Ourmières Y., Zakardjian B., Béranger K., Langlais C. 2011. Assessment of a NEMO-based downscaling experiment for the North-Western Mediterranean region: Impacts on the Northern Current and comparison with ADCP data and altimetry products. Ocean Modelling 39: 386-404.

Petrenko A. 2003. Variability of circulation features in the Gulf of Lion NW Mediterranean Sea. Importance of inertial currents. Oceanol. Acta 26: 323-338.

Petrenko A., Leredde Y., Marsaleix P. 2005. Circulation in a stratified and wind-forced Gulf of Lions, NW Mediterranean Sea: in situ and modelling data. Cont. Shelf Res. 25: 7-27.

Pinardi N., Allen I., De Mey P., Korres G., Lascaratos A., Le Traon P.Y., Maillard C., Manzella G., Tziavos C. 2003. The Mediterranean Ocean Forecasting System: first phase of implementation (1998-2001). Ann. Geophys. 21: 1, 3-20.

Pham D.T., Verron J., Roubaud M.C. 1998. A Singular Evolutive Kalman filter for data assimilation in oceanography. J. Mar. Syst. 16: 323-340.

Reffray G., Fraunié P., Marsaleix P. 2004. Secondary flow induced by wind forcing in the Rhône region of freshwater influence. Ocean Dyn. 54: 179-196.

Uppala S. M., Kallberg P., Simmons A., Andrae U., Bechtold V. D. C., Fiorino M., Gibson J., Haseler J., Hernandez A., Kelly G., Li X., Onogi K., Saarinen S., Sokka N., Allan R., Andersson E. Arpe K., Balmaseda M., Beljaars A., Berg L.V.D., Bidlot J., Bormann N., Caires S., Chevallier F., Dethof A., Dragosavac M., Fisher M., Fuentes M., Hagemann S., Holm E., Hoskins B., Isaksen L., Janssen P., Jenne R., McNally A., Mahfouf J.-F., Morcrette J.-J., Rayer N., SaundersR., Simon P., Sterl A., Trenberth K., Untch A., Vasiljevic D., Viterbo P., Woollen J. 2005. The era-40 re-analysis, Q. J. R. Meteorol. Soc. 131 : 2961-3012, doi : 10.1256/qj.04.176.

Vincent P., Steunou N., Caubet E., Phalippou L., Rey L., Thouvenot E., Verron J. 2006. AltiKa: a Ka-band altimetry payload and system for operational altimetry during the GMES period. Sensors. 6: 208-234.

Scient. ed.: J. Font.

Received May 25, 2011. Accepted March 13, 2012.

Published online August 2, 2012. 